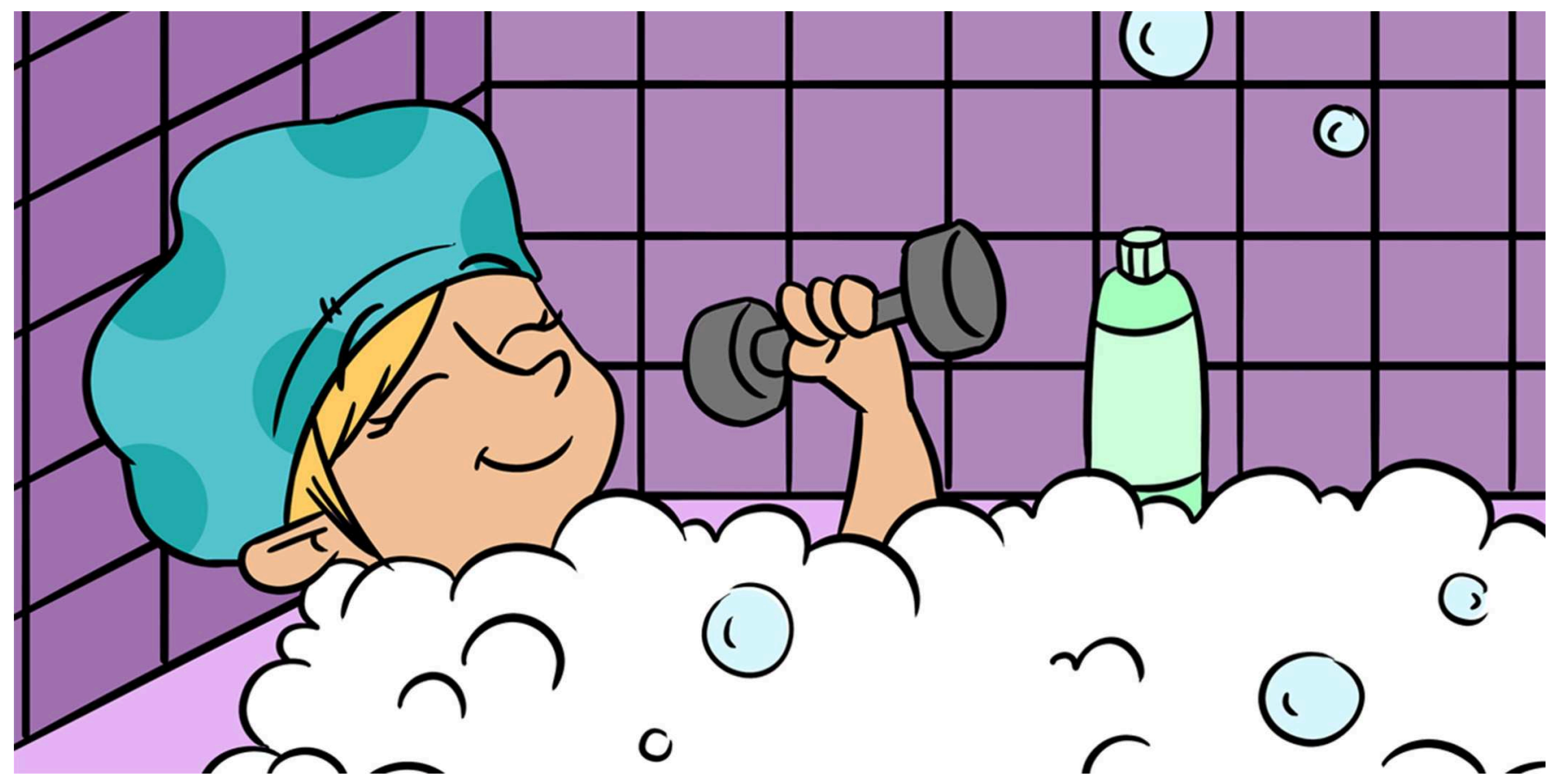

\title{
CAN HOT BATHS IMPROVE HEALTH?
}

\section{Sven P. Hoekstra * and Christof A. Leicht}

The Peter Harrison Centre for Disability Sport, The School of Sport, Exercise and Health Sciences, Loughborough University, Loughborough, United Kingdom

\section{YOUNG REVIEWERS:}

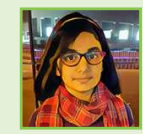

ALAA

AGE: 11

LUANA

AGE: 13
We all know that playing sports like football, tennis, or hockey with friends can be really good fun. Even better, it also helps us to stay healthy. But what if you cannot do exercise because your body does not allow you to? For example, some people with disabilities cannot use their legs and older people are sometimes not strong enough to exercise. For these people, it would be great if there was another activity that could keep them healthy. Since part of the healthy effects of exercise may come from the fact that your body temperature increases when you are running around, getting warm without doing any exercise may also improve people's health. In this study, we investigated whether getting warm by sitting in a hot bath can improve health. We would recommend reading this article while sitting in a bath...

\section{THE PROBLEM: PEOPLE WITH LARGE AMOUNTS OF BODY FAT ARE MORE LIKELY TO GET CHRONIC DISEASES}

You probably remember the last time you were ill: a sore throat, a bad cough, inability to eat as much as normal, and maybe you could not 
TYPE 2 DIABETES MELLITUS

Type 2 diabetes mellitus is a condition in which people have difficulty processing the sugar in the foods they eat. When not treated, this can damage for example your blood vessels.

\section{CHRONIC}

INFLAMMATION

This is the long-term overactivation of the immune system and can increase the risk for chronic diseases. even go to school. Your symptoms, however, probably ended after a few days, leaving you feeling completely fine. You can thank your immune system for your recovery, since it fired up quickly and got rid of the things in your body that made you ill. With chronic diseases, on the other hand, people are ill for a much longer time-sometimes even their whole lives.

One example of a chronic disease that many people in countries, such as the United States and the United Kingdom suffer from is called type 2 diabetes mellitus, which we will just call diabetes 2 . Diabetes 2 is a condition in which people have difficulty processing the sugar in the foods they eat. As a result, the concentration of sugar in the blood can get out of control and cause all sorts of damage. The reasons that people get this condition are not completely clear, but one of the causes may be something called chronic inflammation. This is the long-term overactivation of the immune system. In contrast to the immune system acting like a brief and intense fire to help get rid of a virus in your body when you have a cold, chronic inflammation can be compared to a small campfire that somebody forgot to put out and that keeps on glowing. Chronic inflammation can impair the way organs and tissue process the sugar in foods. Because fat cells in the body contain a lot of over-active immune cells that help to keep the immune campfire glowing, people with high amounts of body fat have a greater chance of getting chronic inflammation. Scientists have suggested that this may be one of the reasons people with more body fat are also more likely to get diabetes 2 [1].

\section{THE GOOD NEWS: EXERCISE MAY HELP TO REDUCE CHRONIC INFLAMMATION}

Luckily, there are ways to put out the immune campfire and reduce chronic inflammation. Although there are pills that may help, exercise is a much cheaper and more fun way of keeping the immune system in check. Indeed, people who exercise have better-balanced, and thus less over-active, immune systems compared with people who never exercise. In addition, studies in which participants complete an exercise program have found that these participants have better-balanced immune systems after the program [2]. Thus, exercise may help to reduce chronic inflammation and therefore also reduce the risk for diseases like diabetes 2 .

But how does exercise do this? It is still uncertain, since there is still a lot we do not know about the human body, but part of the healthy effect of exercise may come from a substances that are produced by the body each time you exercise. When you exercise, your body does not only kick a ball or run around the track-your liver, kidneys, muscles, and brain also produce a lot of these healthy substances. There is one important thing to know about these substances: they might reduce the over-activity of the immune system [3], somewhat 
like fire-fighters that put out the glowing campfires in people with chronic inflammation. Although we measured a few different sorts of fire-fighting substances, the one we focus on here is called interleukin-6 (IL-6).

\section{ANOTHER PROBLEM: WHAT IF PEOPLE ARE NOT ABLE TO EXERCISE?}

So, maybe it sounds easy: we just tell everybody to exercise and the fire-fighters in the blood make sure that people do not get chronic inflammation. But what if your body does not allow you to exercise? Elderly people, for example, sometimes do not have the strength to ride a bicycle or to go for a walk. In other people, disabilities can prevent them from doing exercise. For these people, it is difficult to increase the numbers of fire-fighters by exercising. So, to keep these people healthy, we need an alternative to exercise that stimulates production of the healthy fire-fighting substances.

Researchers from around the world are working on different alternatives for people unable to exercise. For example, there are machines that can use electrical stimulation to help people with paralyzed legs to cycle. Other researchers have found that your body temperature increases when you exercise. Even more interesting is that, when you exercise in the heat (temperature between $\sim 25$ and $35^{\circ} \mathrm{C}$ ), your body produces a larger amount of fire-fighters than when you exercise in colder weather (below $\sim 25^{\circ} \mathrm{C}$ ) [4]. So, getting warm may be important for your body to produce these fire-fighters. If getting warm is indeed important, would that mean that warming people up in the absence of exercise could improve their health? Could we place people in hot water to increase the amount of fire-fighting substance and reduce their risk for diabetes 2?

\section{A POTENTIAL ALTERNATIVE: TESTING THE EFFECTS OF HOT BATHS ON HEALTH}

To test the idea that hot baths might substitute for exercise, we asked 10 male adults with a bit too much body fat to take part in the study. An overview of this study can be seen in Figure 1. To investigate the short-term effects of hot baths, the participants sat in water of $39^{\circ} \mathrm{C}$ for $1 \mathrm{~h}$. Before and after that hour, we took blood samples to measure the amount of the fire-fighting substance.

After the short-term part of the study, participants participated in the long-term part. For this, they took 10 hot baths within 2 weeks. To study whether these 10 hot baths improved the health of our participants, we took blood samples and measured their blood pressure at the start and at the end of the 2 weeks. We measured the amount of sugar in the blood sample. A reduction in blood sugar 
Figure 1

Study to test the shortand long-term effects of hot baths on health. For the short-term study, we collected blood samples before and after one hot bath to measure the concentration of IL-6 (the fire-fighting substance that reduces chronic inflammation). For the long-term part of the study, we collected blood samples and tested them for blood sugar concentration and measured participants' blood pressure before and after taking 10 hot baths over 2 weeks.

\section{CARDIOVASCULAR}

\section{DISEASE}

A collection of diseases affecting the heart and blood vessels. In the most severe cases it can prevent blood going to the brain or even cause the heart to stop beating.

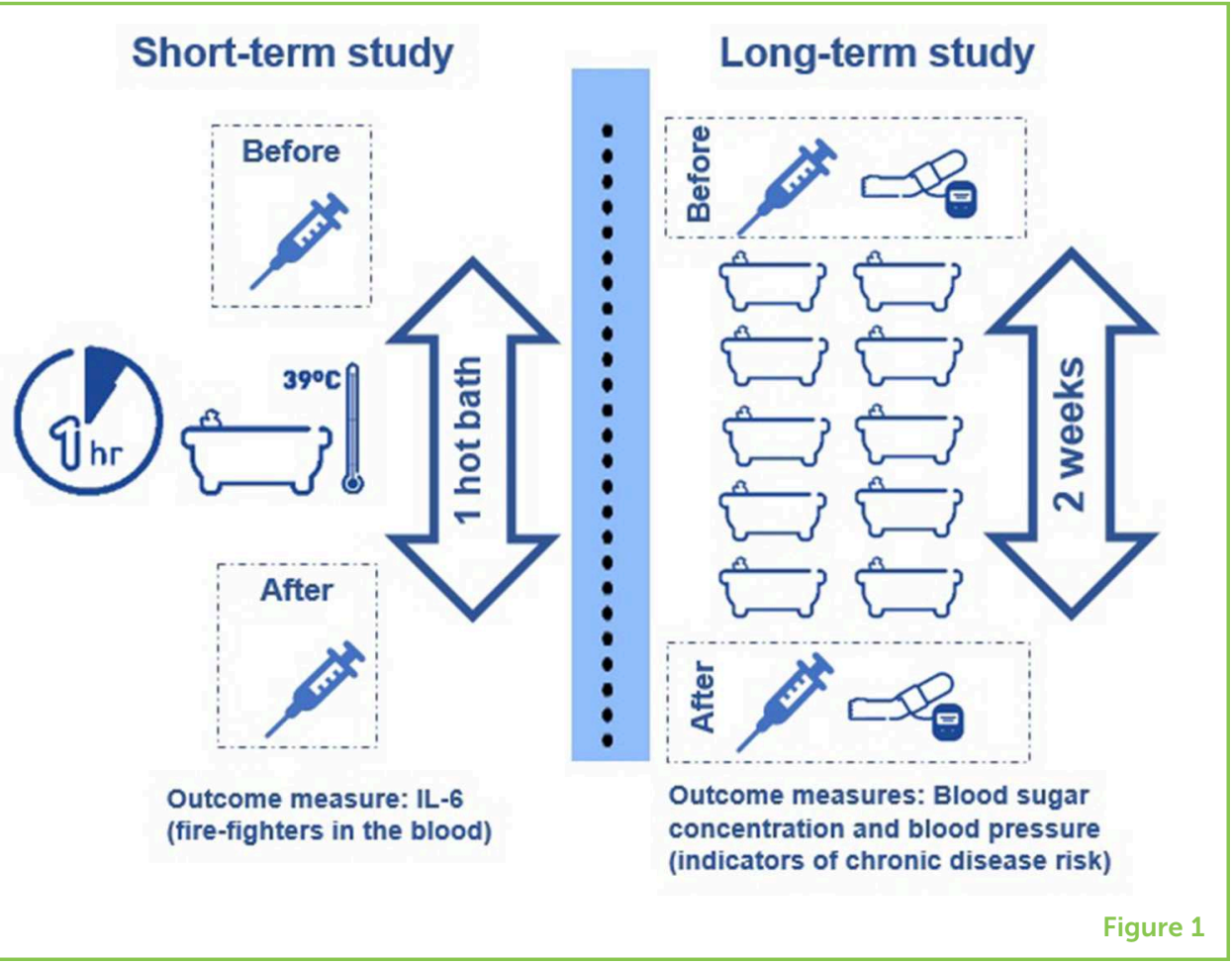

is generally believed to reduce the risk of getting diabetes 2, and a reduction in blood pressure reduces the risk of getting another chronic disease called cardiovascular disease.

\section{STUDY RESULTS: HOT BATHS MAY IMPROVE HEALTH!}

The most important findings of the study are shown in Figure 2. Even one hot bath increased the concentration of the fire-fighting substance IL-6 in the blood. Since we would like to improve people's health for longer than 1 day, the long-term study results are even more important. In the long-term study, we found that, after 10 hot baths within 2 weeks, participants' blood sugar concentrations were lower than they were at the start of the study. Their blood pressure readings were also reduced at the end of the 2 -weeks study period.

\section{THE INTERPRETATION: WHAT DOTHESE RESULTS MEAN?}

The short-term increase in the blood concentration of the fire-fighting substance IL-6, the reduction in blood sugar concentration, and the lowering of blood pressure after the long-term part of the study are promising findings for the use of hot baths as an alternative to exercise. It is, however, important to realize that we still need to know a little bit more before we can advise hot baths for people who are unable to exercise. For example, the long-term part of the study consisted of a lot of hot baths in only 2 weeks' time. Most people are probably too busy with other things, like work, to take this many baths. In the 
Figure 2

Findings from the short- and long-term parts of the study. After one hot bath, the concentration of IL-6, the fire-fighting substance that reduces chronic inflammation, was increased. After 2 weeks during which people had 10 hot baths, both blood pressure and blood sugar concentration were reduced. Both of these measures tell us that there is probably a reduction in the risk of developing a chronic disease, like diabetes 2 or cardiovascular disease.

\section{Short-term findings}

After 1 hot bath:
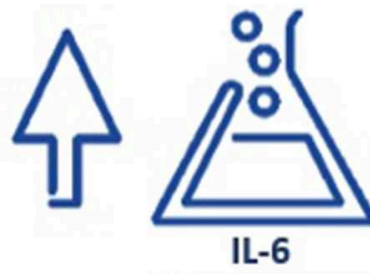

(fire-fighters in the blood)

\section{Long-term findings}

After 2 weeks with 10 hot baths:
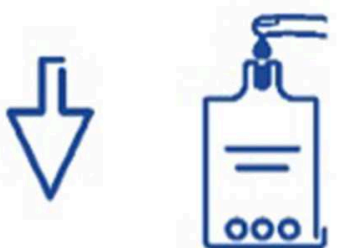

Blood sugar

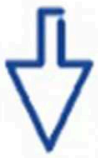

Figure 2

future, we would like to test whether taking fewer baths per week, but over a longer duration, like several months, also improves health. Also, we have only investigated the effects of hot baths in men, and it would be interesting to find out whether baths can also improve health in women.

Another thing to consider is that a bath of $39^{\circ} \mathrm{C}$ for $1 \mathrm{~h}$ makes you feel really, really, warm. Although a hot bath sounds relaxing, feeling that warm can be unpleasant. As a result, people may stop taking hot baths after only 1 week, if they do not like them. To make sure that people keep taking hot baths after their first week, we should come up with ways that these baths can become more pleasant and enjoyable.

\section{THE CONCLUSION: SHOULD WE ALL TAKE HOT BATHS?}

The results of this study are encouraging for the use of hot baths as an alternative for people that cannot exercise. However, before we advise hot baths in such situations, there is still a lot to find out. Maybe one day we will be able to say to these people, "A hot bath a day keeps the doctor away!"

\section{ORIGINAL SOURCE ARTICLE}

Hoekstra S. P., Bishop N. C., Faulkner S. H., Bailey S. J., and Leicht C. A. 2018. The acute and chronic effects of hot water immersion on inflammation and metabolism in sedentary, overweight adults. J. Appl. Physiol. 125:2008-18. doi: 10.1152/japplphysiol.00407.2018 


\section{REFERENCES}

1. Pradhan, A. D., Manson, J. E., Rifai, N., Buring, J. E., and Ridker, P. M. 2001. C-reactive protein, interleukin 6, and risk of developing type 2 diabetes mellitus. JAMA 286:327-34. doi: 10.1001/jama.286.3.327

2. Beavers, K. M., Brinkley, T. E., and Nicklas, B. J. 2010. Effect of exercise training on chronic inflammation. Clin. Chim. Acta 411:785-93. doi: 10.1016/j.cca.2010.02.069

3. Fischer, C. P. 2006. Interleukin- 6 in acute exercise and training: what is the biological relevance? Exerc. Immunol. Rev. 12:41-54.

4. Rhind, S. G., Gannon, G. A., Shephard, R. J., Buguet, A., Shek, P. N., and Radomski, M. W. 2004. Cytokine induction during exertional hyperthermia is abolished by core temperature clamping: neuroendocrine regulatory mechanisms. Int. J. Hyperthermia 20:503-16. doi: 10.1080/02656730410001670651

SUBMITTED: 19 March 2019; ACCEPTED: 01 July 2019; PUBLISHED ONLINE: 18 July 2019.

EDITED BY: Rossana De Lorenzi, Associazione Adamas Scienza, Italy

CITATION: Hoekstra SP and Leicht CA (2019) Can Hot Baths Improve Health? Front. Young Minds 7:98. doi: 10.3389/frym.2019.00098

CONFLICT OF INTEREST STATEMENT: The authors declare that the research was conducted in the absence of any commercial or financial relationships that could be construed as a potential conflict of interest.

COPYRIGHT @ 2019 Hoekstra and Leicht. This is an open-access article distributed under the terms of the Creative Commons Attribution License (CC BY). The use, distribution or reproduction in other forums is permitted, provided the original author(s) and the copyright owner(s) are credited and that the original publication in this journal is cited, in accordance with accepted academic practice. No use, distribution or reproduction is permitted which does not comply with these terms.

\section{YOUNG REVIEWERS}
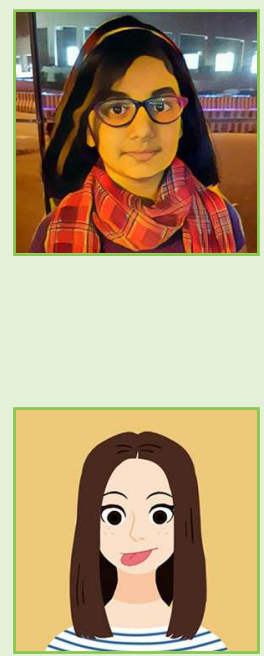

\section{ALAA, AGE: 11}

I love learning. I am an avid reader and a chocoholic. When I grow up, I want to be a pilot or a scientist. I am a nature fanatic and I also love traveling. I have traveled to many fascinating places like Amsterdam, Abu Dhabi, Dubai, Dusseldorf, Frankfurt, London, Vancouver, Victoria, and Whistler and I plan to visit many more in future. I enjoy drawing and coloring, watching cartoons and educational videos. I am on the MMEIS badminton varsity team and I love playing the game.

\section{LUANA, AGE: 13}

I was born in the USA, and have lived in Canada for 5 years. That is why I can speak English so well. Both my parents are scientists (microbiologists), so I think that is why I always have loved science. 


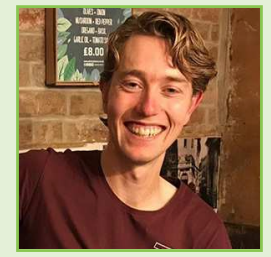

\section{AUTHORS}

\section{SVEN P. HOEKSTRA}

I have recently finished my Ph.D. at Loughborough University and am now working as a researcher at the same university. With the help of other members of our group, The Peter Harrison Centre for Disability Sport (https://www.lboro.ac.uk/ research/phc/), I study alternative activities for people who cannot engage in regular exercise. You can follow all our research activities via Twitter: https://twitter.com/ sven_hoekstra. Besides doing research, I like to run and cycle in the beautiful British countryside. *s.p.hoekstra@lboro.ac.uk

\section{CHRISTOF A. LEICHT}

I am a Lecturer at Loughborough University, which means that I do research and I teach students. When I first heard that getting the body hot might help it to be healthy, I was intrigued because I like going to the sauna. So, I started to do research in this area, looking at various ways to increase body temperature-either by doing exercise, by wearing extra clothing during exercise, or by taking a hot bath. I like trying and finding out new things, mountains, chocolate, and cats. 